\title{
The factors related to mother's beliefs and behaviors concerning the prevention of poisoning among children under the age of five, using the Health Belief Model
}

\author{
Forouzan Rezapur Shahkolai ${ }^{1,2,3}$, Khadijeh Bandehelahi ${ }^{1}$, Akram Karimi Shahanjarini ${ }^{1,3}$, \\ Maryam Farhadian ${ }^{2,4}$ \\ ${ }^{1}$ Department of Public Health, School of Public Health, ${ }^{2}$ Research Center for Health Sciences, ${ }^{3}$ Social Determinants of \\ Health Research Center, ${ }^{4}$ Department of Biostatistics, School of Public Health, Hamadan University of Medical Sciences, \\ Hamadan, Iran. E-mail: bandehalahi@gmail.com \\ Received: 8th July 2018, Revised: 5th September 2018, Accepted: 23rd September 2018
}

SUMMARY: Rezapur Shahkolai F, Bandehelahi K, Karimi Shahanjarini A, Farhadian $\mathrm{M}$. The factors related to mother's beliefs and behaviors concerning the prevention of poisoning among children under the age of five, using the Health Belief Mode. Turk J Pediatr 2019; 61: 749-756.

Poisoning is a major public health problem and children younger than five years of age are more likely to be exposed to injury events such as poisoning.

The aim of this study is to investigate the factors associated with the mothers beliefs and behaviors in relation to poisoning prevention among children under five years of age, considering the Health Belief Model (HBM).

This cross-sectional study was conducted among 580 mothers with at least one child under the age of five that had been referred to a health center in Hamadan County, Iran, in 2017. The participants were selected randomly, using cluster sampling method. Data were collected through interviews, by trained interviewers, and using a questionnaire developed by the authors.

This study showed the statistically significant relationship between mothers' behavior concerning the prevention of poisoning in children under the age of five years and the variables of the gender of children $(\mathrm{P}=0.014)$; mother's education level $(\mathrm{P}<0.001)$ and occupation $(\mathrm{P}=0.001)$; and father's education level $(\mathrm{P}<0.001)$ and occupation $(\mathrm{P}<0.001)$. Moreover, mothers' related knowledge and, according to HBM constructs, mothers' perceived susceptibility $(\mathrm{p}<0.001)$ and perceived severity $(\mathrm{p}=0.004)$ regarding poisoning among their children, cues to action $(p=0.041)$ and their self-efficacy $(p=0.012)$ were more powerful predictors for prevention of poisoning among children under the age of five.

This study indicates that the HBM, highlighting the four constructs can be helpful to design educational interventions for improving the behaviors of mothers regarding poisoning prevention among children under the age of five years.

Key words: unintentional injury, injury prevention, health promotion, health education, Iran.

Poisoning is one of the major public health problems and is one of the most common causes for referring to emergency departments. ${ }^{1-3}$ According to World Health Organization (WHO), an estimated 193,460 people died worldwide from unintentional poisoning in 2012. Of these deaths, $84 \%$ occurred in lowand middle-income countries. ${ }^{1}$ Most children under 5 years die from unintentional injuries that are attributable to the environment, such 
as poisoning, falls, and drowning. ${ }^{4-5}$ Among various external reasons for death in children at the age range from 1 to 14 years, poisoning has been located in fourth-place after road injuries, fires and drowning. ${ }^{1}$ Children are also exposed to harmful chemicals through food, water, air and products around them. ${ }^{4}$ Based on WHO definition, poisoning is a term used to describe an event where the poisonous substances have entered the body through breathing, mouth, blood vessels, eating, injections, and leads to the destruction and death of the body's cells. ${ }^{6}$ Studies show that children younger than five years are more likely to be exposed to events such as poisoning. ${ }^{7}$ According to statistics provided by forensic medicine in Iran, this injury type has introduced the second cause of child mortality. According to the results of a meta-analysis and a country's estimate, it has been detected that the rate of poisoning is still high in Iran. ${ }^{8}$ In industrial countries, poisoning occurs more with drugs, but in developing countries, poisoning occurs more often with poisons. ${ }^{9}$ Injuries (including poisoning) are economically important due to financial losses. ${ }^{10}$ Results of previous studies illustrate that effective strategies for preventing poisoning among children have been identified, which is including safe maintenance of drugs at home, education of mothers and children for preventing the ingestion of toxic substances, accurate labeling of toxic products, providing non-penetrating packages of pills and so on for children. ${ }^{5}$ Identifying the determinants of adopting the preventive behaviors for children's poisoning is an introduction to prevention. The results of a study conducted in Iran showed that one of the important factors in prevention of domestic events in children, e.g., poisoning is the attitude and behavior of mothers of children under five years of age towards preventing these events. ${ }^{11}$ The researches highlight the importance of conducting the related studies based on health education and promotion models and theories that affect the psychological factors influencing individuals' knowledge and attitude and can help to prevent the injury events by them. Experts believe that the effectiveness of behavior change and health education programs is dependent on proper use of health education models and theories. Therefore, in the first step of the health education program, an appropriate model should be selected. ${ }^{12}$ The Health Belief Model (HBM) was invented by sociologists, psychologists and healthcare professionals and can help to adopt health behaviors. It also can help to explain and to predict health behaviors among people. This model consists of the constructs including perceived susceptibility, perceived severity, perceived benefits, perceived barriers, cues to action, and self-efficacy. ${ }^{13}$ The purpose of this study is to investigate the factors associated with mothers' beliefs and behaviors in relation to poisoning prevention among children under five years of age, concerning HBM constructs.

\section{Material and Methods}

This study was a cross-sectional study. It was conducted in Hamadan County, located in the west of Iran, from June 13 to August 14, 2017. This study was conducted with 580 mothers, who had at least one child under the age of five. Sampling was done randomly using cluster sampling method. To compute sample size, similar studies were not found. Therefore, the prevalence of preventive behavior of poisoning of the mothers were considered as $\mathrm{p}=50 \%$. Accordingly, to calculate the sample size for this study the related formula was used $\left(\mathrm{n}=\frac{\mathrm{z}_{1-\frac{\alpha}{2}}^{2} \mathrm{p}(1-\mathrm{p})}{\mathrm{d}^{2}}=384\right)$ and also considering

the design effect (design effect=1.5), the final sample size was calculated as 580 in this study. In this formula, we used 0.95 as a confidence level and 0.05 as the estimated error. The mothers who came to health centers, including eight urban and five rural health centers, to receive the routine nursing care for children under age of five years old in sampling days were involved in this study. In each urban health center, a number of 48 individuals and in each rural health center a number of 40 individuals participated in the study. It is noteworthy that all the participants were informed about the aim and importance the study and the confidentiality of the information. They were included in the study, after giving informed consent. In this study having a maternal health record in the health center and having at least one child under the age of five were the inclusion criteria. Also 
in this study lack of consent to complete the interview and family immigration from the study setting and mother physical or mental disability were the exclusion criteria. In the current study, the interview method was used to collect data which was performed by three trained interviewers. During the interview, there was one person to take care of the mother's child so that the mother could participate in the interview and answer the questions easily. The data gathering tool was a researcher-made questionnaire that included demographic questions, questions about mothers' knowledge, behavior in relation to poisoning prevention among children and also their related beliefs based on the HBM constructs. The demographic questions included age, sex, the status of parental education and occupation and manner of child caring. The dependent variable in this study was the behavior of mothers in relation to preventing poisoning among children under the age of five years and independent variables included knowledge and the constructs of the HBM. Measuring the mothers' knowledge towards the prevention of poisoning in children was performed using ten multiple choice questions. There were four options to response to each question including one correct and three wrong options (one example of knowledge related question: 'what is the most common cause of child poisoning?'). To measure each construct of the HBM, the Likert scale question of five options (strongly agree to strongly disagree) were used. To measure the construct of perceived susceptibility or perception of mothers about the vulnerability of their children regarding poisoning six items were used (one example: 'There is a possibility that poisoning could cause a disability in my child'). The perceived severity construct consisted of five items (one example: 'Severe poisoning cause's trouble in future lives of children'). These items were about the perception of mothers regarding the severity and consequences of poisoning in their children. The assessment of the perceived benefits construct included three items (one example: 'Caring for my child and attention to her/his poisoning safety can reduce the cost of treatment for my family'). This construct was related to the perception of mothers towards the benefits derived from preventive measures against poisoning in children.
The measurement of the perceived barriers included five items (one example: 'Supervising the activities of my child regarding her/his poisoning safety is time consuming and takes my time'). This construct was related to the perception of mothers about the barriers to prevention of the poisoning among children. The cues to action consisted of five items (one example: 'Health workers instruct me about the principles of safety and the prevention of children poisonings'). This construct was about the existing cues for mothers to perform the preventive measures against poisoning among children. Measurement of self-efficacy construct consisted of five items (one example: 'I am certain that I can keep my child safe at any time'). This construct was related to the ability of mothers to implement the preventive measures to prevent poisoning among children. The number of behavioral questions was eleven, having two options for answers (yes / no), and were related to home safety and maternal safety measures to prevent poisoning among children that were self-reported. A higher score reflects better behaviors of the mothers in this regard (two examples of the behavior related questions: 1) 'I keep cleaning and bleaching chemicals in locked cabinets and away from my child's reach at home' and 2) 'I keep medications such as tablets, syrups in the lower floors of the refrigerator'.

In this study, the rate of participation of mothers and responding to the questionnaire was $100 \%$. To investigate the validity of the questionnaire it was reviewed and corrected and revised by a panel of experts. Moreover, in order to investigate the reliability of the questionnaire, it was completed by 30 mothers in a preliminary study. To test the reliability of the questionnaire, the test-retest method was used with a two-week interval and the values of $r=0.93$ and $p$ value $=0.001$ were obtained, which they were acceptable values. Meanwhile, the total amount of Cronbach alpha value obtained from questionnaires was equal to 0.8. The Cronbach alpha value for the constructs of the HBM was as follows: knowledge: 0.80 ; perceived susceptibility: 0.80 ; perceived severity: 0.77 ; perceived barriers: 0.80; perceived benefits: 0.77 ; cues to action: 0.80 ; self-efficacy: 0.87 and behaviors: 0.80 . 
Data were analyzed using SPSS 21 and both descriptive methods and statistical tests including one way ANOVA, regression and independent t-test were conducted.

This research project has been approved by the Ethics Committee for Research (ID: IR.UMSHA.REC.1396.7) at Hamadan University of Medical Sciences.

\section{Results}

The results of this study show that among the constructs of HBM, the perceived susceptibility, perceived severity, cues to action and self-efficacy were found to be the stronger predictors of preventative behaviors of mothers towards preventing poisoning in children under the age of five years. It should be noted that no child was reported to experience poisoning in this study.

Table I shows the demographic characteristics of participants. According to this table, most of the mothers $(45.7 \%)$ were in the age group of 26-30 years and the most of the fathers $(33.3 \%)$ of children were in the age group of 31-35 years. The majority of the mothers $(65.5 \%)$ were living in the city. Both mothers and fathers' education levels were at secondary school level. Most of the fathers (42.1\%) were self-employed and most of the mothers were housewives (94.8\%). Mothers had mostly (46.4\%) only one child and also had only one child under five-year-old (83.8\%). Most of the children $(96.6 \%)$ were looked after by their mothers at home.

In Table I the one-way ANOVA test and T-test also shows the relationship between the demographic variables of the study and the behaviors of the mothers in the prevention of poisoning among children. It was found that there was a statistically significant relationship between mothers' behavior in preventing poisoning among children under the age of five years and the variables of the age of the father in the family $(\mathrm{P}=0.001)$; gender of children $(\mathrm{P}=0.014)$; place of residence $(\mathrm{P}<0.001)$; mother's education level $(\mathrm{P}<0.001)$; mother's occupation ( $\mathrm{P}=0.001)$; father's education level $(\mathrm{P}<0.001)$; father's occupation $(\mathrm{P}<0.001)$ and children nursing manner $(\mathrm{P}=0.016)$.
Table II presents the mean, standard deviation of the mothers' knowledge, preventive behaviors, and their beliefs according to the HBM constructs. This table shows that, among the studied constructs and regarding the range of obtainable scores for each construct, the preventive behaviors of mothers towards the poisoning among children and the perceived barrier construct are in the highest and lowest levels, respectively. Also all constructs of the HBM were higher than the moderate level in this study.

Table III shows the relationship between the HBM constructs and the behaviors of preventing poisoning among children. The Regression Model between behaviors (response variable) and constructs of HBM (independent variable) was applied.

There was a significant positive correlation between the mothers' behaviors in preventing poisoning in children under five years of age and knowledge $(\mathrm{P}<0.001)$; perceived susceptibility $(\mathrm{P}<0.001)$; perceived severity $(\mathrm{P}=0.004)$; cues to action $(\mathrm{P}=0.041)$ and selfefficacy $(\mathrm{P}=0.012)$.

\section{Discussion}

In this study, the factors related to the behaviors of mothers regarding the prevention of poisoning among children under the age of five, using the HBM, were investigated. Regarding the HBM, this study showed that the preventive behaviors of mothers towards poisoning among children and the perceived barrier construct were in the highest and lowest levels, respectively. These results were consistent with a similar study on injury among under-five year old children in which, for all of the various constructs of the HBM, the mean scores were reported in moderate and/or in higher than moderate levels. ${ }^{14}$ Based on the results of the studies, it has been shown that, preventing behaviors can be increased by identifying and removing the barriers and through educational interventions and also increasing perceived susceptibility, severity benefits, self-efficacy, and cues to action. ${ }^{14-15}$

Various factors are effective in forming and initiating risky behavior in the home, including the social and economic status of the 
Table I. Relationship between Demographic Variables and Mothers' Behaviors Concerning the Prevention of Poisoning among Children under Five Years of Age $(n=580)$.

\begin{tabular}{|c|c|c|c|c|}
\hline Demographic variables & & Frequency (\%) & $\begin{array}{c}\text { Behavior mean } \\
\text { score } \pm \\
\text { standard division }\end{array}$ & P-value \\
\hline \multirow[t]{5}{*}{ Mother's age } & $15-20$ years old & $16(2.8)$ & $9.88 \pm 1.02$ & 0.091 \\
\hline & 21-25 years old & $110(19)$ & $9.88 \pm 1.11$ & \\
\hline & $26-30$ years old & $265(45.7)$ & $10.16 \pm 0.93$ & \\
\hline & $31-35$ years old & $138(23.8)$ & $10.14 \pm 0.88$ & \\
\hline & 36 years old and higher & $51(8.8)$ & $10.06 \pm 0.95$ & \\
\hline \multirow[t]{5}{*}{ Father's age } & Under 25 years of old & $28(4.8)$ & $10.18 \pm 0.86$ & 0.001 \\
\hline & $26-30$ years old & $180(31)$ & $10.05 \pm 1.02$ & \\
\hline & $31-35$ years old & $193(33.3)$ & $10.07 \pm 0.95$ & \\
\hline & $36-40$ year old & $136(23.4)$ & $10.29 \pm 0.85$ & \\
\hline & 40 years old and higher & $43(7.4)$ & $9.60 \pm 0.95$ & \\
\hline \multirow{2}{*}{$\begin{array}{l}\text { The number of children } \\
\text { under age of } 5 \text { in family }\end{array}$} & 1 & $486(83.8)$ & $10.06 \pm 0.96$ & 0.107 \\
\hline & 2 & $94(16.2)$ & $10.23 \pm 0.92$ & \\
\hline \multirow{2}{*}{$\begin{array}{l}\text { Gender of } \\
\text { children }\end{array}$} & Male & $373(64.3)$ & $10.16 \pm 0.92$ & 0.014 \\
\hline & Female & $207(35.7)$ & $9.96 \pm 1.02$ & \\
\hline \multirow[t]{2}{*}{ Place of residency } & City & $380(65.5)$ & $10.23 \pm 0.92$ & $<0.001$ \\
\hline & Village & $200(34.5)$ & $9.82 \pm 0.98$ & \\
\hline \multirow[t]{6}{*}{ Mother's education } & Illiterate & $12(2.1)$ & $9.83 \pm 1.03$ & $<0.001$ \\
\hline & Primary (grade 1- 5) school & $82(14.1)$ & $9.63 \pm 1.11$ & \\
\hline & Secondary school (grade 6-8) & $156(26.9)$ & $9.96 \pm 0.89$ & \\
\hline & High school (grade 9-12) & $115(19.8)$ & $10.16 \pm 0.9$ & \\
\hline & Diploma & $132(22.8)$ & $10.20 \pm 0.96$ & \\
\hline & University & $83(14.3)$ & $10.24 \pm 0.75$ & \\
\hline \multirow[t]{2}{*}{ Mother's occupation } & House wife & $550(94.8)$ & $10.06 \pm 0.96$ & 0.001 \\
\hline & Employed & $30(5.2)$ & $10.64 \pm 0.72$ & \\
\hline \multirow[t]{6}{*}{ Father's education } & Illiterate & $18(3.1)$ & $9.56 \pm 0.98$ & $<0.001$ \\
\hline & Primary school（grade 1-5) & $84(14.5)$ & $9.65 \pm 1.01$ & \\
\hline & Secondary school (grade 6-8) & $186(32.1)$ & $9.96 \pm 0.95$ & \\
\hline & High school (grade 9-12) & $82(14.1)$ & $10.12 \pm 0.91$ & \\
\hline & Diploma & $113(19.5)$ & $10.27 \pm 0.88$ & \\
\hline & University & $97(16.8)$ & $10.61 \pm 0.71$ & \\
\hline \multirow[t]{5}{*}{ Father's occupation } & Self-employed & $244(42.1)$ & $10.14 \pm 0.96$ & $<0.001$ \\
\hline & Worker & $125(21.6)$ & $9.71 \pm 0.99$ & \\
\hline & Farmer & $90(15.5)$ & $10.10 \pm 0.84$ & \\
\hline & Employee & $70(12.1)$ & $10.45 \pm 0.88$ & \\
\hline & Unemployed & $51(8.8)$ & $10.24 \pm 0.93$ & \\
\hline \multirow{3}{*}{$\begin{array}{l}\text { The manner of children } \\
\text { nursing }\end{array}$} & By mothers & $560(96.6)$ & $10.07 \pm 0.96$ & 0.016 \\
\hline & In kindergarten & $11(1.9)$ & $10.91 \pm 0.30$ & \\
\hline & By a person except mother & $9(1.6)$ & $10.11 \pm 1.05$ & \\
\hline
\end{tabular}


Table II. Descriptive Results of Knowledge, Constructs of the Health Belief Model and Behaviors among Mothers with Children under Five Years of Age.

\begin{tabular}{lcccc}
\hline Constructs & Mean & Standard deviation & Obtainable score range & Score, obtained \\
\hline Knowledge & 6.01 & 1.70 & $0-10$ & $1-10$ \\
$\begin{array}{l}\text { Perceived } \\
\text { susceptibility }\end{array}$ & 23.10 & 3.32 & $6-30$ & $10-30$ \\
Perceived severity & 19.60 & 2.71 & $5-25$ & $11-25$ \\
Perceived barriers & 15.00 & 3.70 & $4-25$ & $5-25$ \\
Perceived benefits & 12.01 & 1.68 & $3-15$ & $4-15$ \\
Cues for action & 16.59 & 4.71 & $4-25$ & $5-25$ \\
Self-efficacy & 15.04 & 2.74 & $4-20$ & $4-20$ \\
Behaviors & 10.09 & 0.96 & $0-11$ & $6-11$ \\
\hline
\end{tabular}

Table III. The Fitted Regression Model between Behaviors (Response Variable) and Constructs of Health Belief Model (Independent Variable).

\begin{tabular}{lccccc}
\hline Variable & $\begin{array}{c}\text { Regression } \\
\text { coefficient }\end{array}$ & $\begin{array}{c}\text { Standardized } \\
\text { regression coefficient }\end{array}$ & $\begin{array}{c}\text { The standard } \\
\text { error }\end{array}$ & P-value & R-squared \\
\hline Knowledge & 0.198 & 0.351 & 0.022 & $<0.001$ & 0.123 \\
$\begin{array}{l}\text { Perceived } \\
\text { susceptibility }\end{array}$ & 0.055 & 0.191 & 0.012 & $<0.001$ & 0.036 \\
Perceived severity & 0.042 & 0.120 & 0.015 & 0.004 & 0.014 \\
Perceived barriers & 0.007 & 0.027 & 0.011 & 0.513 & 0.001 \\
Perceived benefits & 0.022 & 0.039 & 0.024 & 0.344 & 0.002 \\
Cues to action & 0.017 & 0.085 & 0.008 & 0.041 & 0.007 \\
Self-efficacy & 0.037 & 0.105 & 0.014 & 0.012 & 0.011 \\
\hline
\end{tabular}

family, the age and sex of the child, the age of the mother, the parents' education, the family size, parental supervision and substance abuse in the family. ${ }^{16}$ In current study, there was a significant correlation between mothers' behaviors in preventing the poisoning among children under the age of five years and demographic variables of father's age, gender of children, place of residence, mother's education, mother's occupation, father's education, father's occupation and children nursing manner. These findings are consistent with a similar study in the field of incidents and poisoning. ${ }^{17}$

In some other studies, the relationships between demographic variables and HBM have been also been measured. For instance, in a study, there was a relationship between perceived severity and gender among underfive year old children and the mean score of perceived severity was higher in mothers with male children than in mothers with female children. There was also a negative significant correlation between the number of children and the self-efficacy construct. The results of this study showed the direct relationships between the number of children, mother's education and mother's age with perceived barriers. ${ }^{18}$

In the current study, there was a significant relationship between knowledge and behavior of mothers in preventing poisoning of children under the age of five years, which is consistent with similar studies. ${ }^{19}$ In order to improve the behavior of mothers, it is necessary to improve the attitude and increase the motivation of mothers. These findings are consistent with a similar study in the field of poisoning. ${ }^{19}$

There were positive and significant relationships between mothers' behaviors in preventing poisoning among children 
under the age of five and their perceived susceptibility, perceived severity, cues to action and self-efficacy. This finding was consistent with a similar study on injury among underfive children using HBM. ${ }^{18}$ The perceived susceptibility construct can be considered as an indicator that prompts mothers to care for their children against poisoning. This finding is not consistent with another similar study on injuries, which may be due to demographic and cultural differences in the groups of studied mothers or the use of different data collection tools. ${ }^{18}$ A similar study that used HBM, showed that some HBM constructs play an important role in adopting preventive behaviors. ${ }^{20-21}$

In another study which in contrary to the findings of this study, the perceived barriers were found to be the most important construct for predicting the preventive behavior of mothers towards the injuries among children under the age of five, and the preventive behaviors of mothers were reduced by increasing the perceived barriers. ${ }^{18}$

The barriers, mentioned in this study, included the need of enough time for promoting home appliance safety. The differences between the demographic characteristics of the two communities under study can be considered as the reasons for the inconsistency of the mentioned study with the results of the present study.

The current study indicates that in designing and implementing effective interventions to prevent poisoning among children, it is good to focus on empowering children's mothers, and also in educating mothers it is important to consider and work on the constructs of perceived susceptibility, perceived severity, cues to action and self-efficacy in relation to the preventive behaviors of mothers.

It seems that one of the important strengths of this study is the full participation of mothers who were selected as a sample $(100 \%$ response rate). The study aim, which was about the participants' children's health and safety, and also having a person to care for the participant's child during the interview both seem to be effective in increasing the response rate. The method of data collection by self- reporting can be referred to as the limitation of the current study. Of course, we tried to discuss the importance of the study to get correct data as much as possible. Also, the data collection in rural area, regarding to be far from some of the villages from the city, was time consuming.

Consequently, the rate of all constructs of the HBM were higher than the moderate level in this study, but regarding importance of safety among children, mothers' behaviors in preventing poisoning in children under the age of five years still need to be promoted. The mothers' behaviors in relation to preventing poisoning among children under the age of five can be predicted based on the constructs of HBM with emphasis on perceived sensitivity, perceived severity, cues to practice and selfefficacy. These findings can be useful to design more appropriate educational interventions in the field of poisoning prevention among children under-five.

\section{Acknowledgments}

This project has been approved and financially supported by the Research and Technology Deputy of Hamadan University of Medical Sciences (reference number: 960115157). The authors wish to thank all the interviewers who helped to collect data in this study and also all mothers who participated in current study.

\section{REFERENCES}

1. World Health Organization. Poisoning Prevention and Management. http://www.who.int/ipcs/poisons/en. (Accessed on 28 December 2019).

2. Sahin S, Carman KB, Dinleyici EC. Acute poisoning in children; data of a pediatric emergency unit. Iran J Pediatr 2011; 21: 479-484.

3. Wynn PM, Zou K, Young B, et al. Prevention of childhood poisoning in the home: overview of systematic reviews and a systematic review of primary studies. In J Inj Contr Saf Promot 2016; 23: 3-28.

4. World Health Organization. The cost of a polluted environment:1.7 million child deaths a year says WHO. https://www.who.int/news-room/detail/0603-2017-the-cost-of-a-polluted-environment-1-7million-child-deaths-a-year-says-who. (Accessed on 30 December 2019). 
5. Rezapur-Shahkolai F, Afshari M, Moghimbeigi A, Hazavehei SMM. Home-related injuries among under-five-year children and mothers' care regarding injury prevention in rural areas. Int J Inj Contr Saf Promot 2017; 24: 354-362.

6. Peden M, Oyegbite K, Ozanne-Smith J , et al. World report on child injury prevention: World Health Organization. 2008: 105-118.

7. Forjuoh SN. Does improving poison prevention practices reduce childhood poisoning rates. Int J Inj Contr Saf Promot 2016; 23: 1-2.

8. Bagheri P, Sepand M. A meta analytical study of intentional and accidental non-food poisoning incidences in Iran (1991-2013) Koomesh 2015; 16: 443-453[in Persian].

9. Gajalakshmi V, Peto R. Suicide rates in rural Tamil $\mathrm{Nadu}$, South India: verbal autopsy of 39000 deaths in 1997-98. Int J Epidemiol 2007; 36: 203-207.

10. Murray CJL, Lopez AD. The global burden of disease: a comprehensive assessment of mortality and disability from diseases, injuries, and risk factors in 1990 and projected to 2020. https://apps.who.int/ iris/handle/10665/41864. (Accessed on 7 January 2020).

11. Cheraghi P, Poorolajal J, Hazavehi SM, RezapurShahkolai F. Effect of educating mothers on injury prevention among children aged $<5$ years using the Health Belief Model: a randomized controlled trial. Public Health 2014; 128: 825-830.

12. Butler JT. Principles of Health Education and Health Promotion.(3rd ed). Wadsworth: Belmont, 2001.

13. Glanz K, Lewis FM, Rimer BK (eds). Health Behavior and HealthEducation: Theory, Research and Practice, (2nd edt). San Francisco: Jossey-Bass, 2008.
14. Poorolajal J, Cheraghi P, Hazavehei SMM, RezapurShahkolai F. Factors associated with mothers' beliefs and practices concerning injury prevention in under five-year children, based on health belief model. J Res Health Sci 2012; 13: 63-68.

15. Jarrah SS, Halabi JO, Bond AE, Abegglen J. Iron deficiency anemia (IDA) perceptions and dietary iron intake among young women and pregnant women in Jordan. J Transcult Nurs 2007; 18: 19-27.

16. Norman RE, Byambaa M, De R, Butchart A, Scott $\mathrm{J}$, Vos T. The long-term health consequences of child physical abuse, emotional abuse, and neglect: a systematic review and meta-analysis. PLoS Med 2012; 9: e1001349.

17. Beirens TM, van Beeck EF, Dekker R, Brug J, Raat H. Unsafe storage of poisons in homes with toddlers. Accid Anal Prev 2006; 38: 772-776.

18. Shekhi MF, Shamsi M, Khorsandi M, Heaidari M Predictors accident structures in mothers with children under 5 years old in city of Khorramabad based on Health Belief Model. J Safety Promot Inj Prev 2015; 3: 199-206 [in Persian].

19. Bilgen Sivri B, Ozpulat F. Mothers' knowledge levels related to poisoning. Turk J Emerg Med 2015; 15: 13 22.

20. Razi T, Shamsi M, Khorsandi M, Roozbahani N, Ranjbaran M. Assessing health belief model construct in paying attention to danger signs in children less than five years old. J Mazandaran Univ Med Sci 2015; 25: 218-223 [in Persian].

21. Ross TP, Ross LT, Rahman A, Cataldo S. The bicycle helmet attitudes scale: using the health belief model to predict helmet use among undergraduates. JAm Coll Health 2010; 59: 29-36. 